\title{
HISTORIA Y CONFIGURACIÓN DEL PATRIMONIO CARTOGRÁFICO DEL IES ALFONSO VIII DE CUENCA
}

\author{
History and the configuration of the educational cartographic \\ heritage of the Alfonso VIII Secondary School of Cuenca
}

\section{Óscar Serrano Gil ${ }^{\alpha}$ y Jesús López Requena ${ }^{\beta}$}

Fecha de recepción: 11/11/2020 • Fecha de aceptación: 14/09/2021

Resumen. La enseñanza de la Geografía ha requerido la necesaria utilización de mapas como un importante instrumento en el aprendizaje de la representación de la Tierra. Los centros educativos, de distintos niveles, han configurado con el paso del tiempo un interesante y rico patrimonio cartográfico el cual se presenta, la mayoría de las veces, muy desconocido. En este trabajo, se plantea la génesis de la colección, la descripción de la metodología aplicada en el proceso de catalogación, y la presentación de los recursos cartográficos procedentes de la cartoteca del Instituto de Educación Secundaria Alfonso VIII (Cuenca) gestada a finales del siglo XIX y conformada por más de doscientas reproducciones de diferentes procedencias (Francia, Italia, Alemania, Austria, Suiza, y Argentina entre otros) abundando las cartas murales destinadas principalmente al proceso de enseñanza-aprendizaje de la disciplina geográfica en el aula. Hoy en día el uso de los mismos se encuentra en franco retroceso pero la idea de revalorizar el legado histórico constituido por esta cartoteca con el valor añadido que atesora ahonda en los valores de una educación en patrimonio.

Palabras clave: Cartoteca; Didáctica de la Geografía; Patrimonio cartográfico educativo; Educación secundaria.

\footnotetext{
^ Dpto. de Didácticas Específicas, Facultad de Formación del Profesorado y Educación, Universidad Autónoma de Madrid. C/ Francisco Tomás y Valiente, 3, (Campus de Cantoblanco). 28049, Madrid, España. oscar.serrano@uam.es (D) https://orcid.org/0000-0002-4483-2533.
}

^ Dpto. de Orientación, IES Alfonso VIII. C/ Lope de Vega,1. 16002, Cuenca, España. jlrequena@edu. jccm.es (D) https://orcid.org/0000-0001-5966-1864.

Cómo citar este artículo: Serrano Gil, Óscar y López Requena, Jesús. «Historia y configuración del patrimonio cartográfico del IES Alfonso VIII de Cuenca». Historia y Memoria de la Educación 15 (2022): 547-576 
Abstract. The teaching of geography has required the use of maps as an important tool in learning how to represent the Earth. Educational institutions have configured a scarcely known but interesting and rich cartographic heritage over time. This work shows the origin of the collection, the methodology, and the presentation of the cartographic resources contained in the map library of the Alfonso VIII Secondary Education Institute of Cuenca. This map collection was created at the end of the 19th century. It brings together more than two hundred reproductions from different places (France, Italy, Germany, Austria, Switzerland, and Argentina). Wall maps used widely in teaching-learning processes prevail. Although maps are used much less today, their reevaluation can contribute the historical legacy based on values of heritage education.

Keywords: Map library; Geography teaching; Educational cartographic heritage; Secondary education.

\section{CONTEXTO INSTITUCIONAL}

El modelo de enseñanza desplegado desde mediados del siglo XIX, en la mayoría de los centros educativos de segunda enseñanza, apostará por una tendencia mayoritaria hacia la formación holística e integradora en lo que a conocimientos, saberes y destrezas se refiere abarcando toda la persona, hecho que se materializará en la ampliación progresiva del patrimonio educativo de recursos didácticos para la impartición de las clases por parte de los docentes. Esta misma circunstancia se plasmará también en la configuración de la cartoteca del Instituto de Educación Secundaria (IES) Alfonso VIII.

Este centro se funda a instancias de la Diputación Provincial mediante una Real Orden de 5 de octubre de 1844 que acordaba crear «un instituto elemental de segunda enseñanza en la capital de la provincia de Cuenca» ${ }^{1}$ de forma que la matrícula del primer curso estaba compuesta por cincuenta y nueve alumnos. ${ }^{2}$ Su primera sede estuvo en pleno centro histórico de la ciudad, en la iglesia de la Merced, hasta el año 1861. ${ }^{3}$ Su vida

\footnotetext{
${ }^{1}$ Ministerio de la Gobernación, «Real Orden creando en la capital de la provincia de Cuenca un instituto de segunda enseñanza», Boletín Oficial de la Instrucción Pública, (1844): 637.

http://hemerotecadigital.bne.es/issue.vm?id=0059094964\&search=\&lang=en (consultado el 07-072020)

2 Jaime Fernández Cursach, "Apuntes para la historia del Alfonso VIII. Los orígenes del instituto», Olcades vol. I, n. ${ }^{\circ} 5$ (1981): 241.

3 Jaime Fernández Cursach, «Apuntes para la historia del Alfonso VIII. La cuestión del local», Olcades vol. II, n. ${ }^{\circ} 9$ (1982): 123-134.
} 
no fue fácil y fue suprimido el 4 de octubre de 1850. Por iniciativa ciudadana se exigió su reapertura, ante la decadencia de la enseñanza en la ciudad, hecho que se materializó en septiembre de 1851.

A partir de 1861 contará con sede propia situada en el Parador de las Escuelas del obispo Palafox (actual Conservatorio Superior de Música Pedro Aranaz) en la calle Palafox. En esta ubicación sufrió el saqueo de los carlistas en julio de 1874 y también presenció la incorporación de la mujer al sistema educativo, primero en las aulas, y posteriormente en la gestión del centro (claustro de profesores). En este sentido, la primera alumna documentada, D. ${ }^{a}$ Ana Sánchez Vera, superó el examen de ingreso en el año 1878. ${ }^{4}$ Unos años después, en 1921, logró por oposición la Cátedra de Lengua y Literatura Francesas del instituto $\mathrm{D}^{\mathrm{a}}$. Luisa Alonso Duro y Guerra, que reclamaba para sí haber sido la primera mujer que formase parte de un claustro de catedráticos en España. ${ }^{5}$

El instituto volverá a cambiar de ubicación en 1946, instalándose en la calle Lope de Vega, ya con el nombre de Alfonso VIII. Tres años después surgirá una revista informativa impulsada por el centro, Perfil, confeccionada por alumnos y profesores. En el año 1993 se inaugura el museo «Juan Giménez de Aguilar» dentro de las instalaciones de la institución, que conserva y expone su patrimonio. También custodia un importante archivo, con el nombre de «Juan José Gómez Brihuega» y una extensa biblioteca denominada «Juan Martino Casamayor».

La corporación municipal le otorgó la Medalla de Oro de la ciudad el 31 de octubre de 2014 y recibió el 16 de junio de 2015 la declaración de Instituto Histórico de Castilla-La Mancha ${ }^{6}$, por parte de la Junta de Comunidades de Castilla-La Mancha, subrayando el legado y patrimonio histórico y educativo que atesora.

\footnotetext{
${ }^{4}$ María Jesús González Izquierdo, «El instituto histórico de Cuenca. Aproximación histórica» en V Jornadas de Institutos Históricos Españoles, (Cabra, Córdoba: Fundación Aguilar y Eslava, 2012), 103-114.

5 «La mujer en la cátedra». El Imparcial (Madrid), año LVII, n. ${ }^{\circ}$ 20.081, 12 de junio de 1923.

6 Junta de Comunidades de Castilla-La Mancha, «Resolución de la Dirección General de Organización, Calidad Educativa y Formación Profesional, por la que se aprueba declarar Instituto Histórico de Castilla-La Mancha al Instituto de Educación Secundaria Alfonso VIII de Cuenca», Diario Oficial de Castilla-La Mancha, (2015), año XXXIV, nº. 122: 20761.

https://docm.castillalamancha.es/portaldocm/descargarArchivo.do? ruta=2015/06/24/pdf/2015_7642. pdf\&tipo=rutaDocm (consultado 08-07-2020)
} 


\section{METODOLOGÍA DE TRABAJO}

La colección de mapas ha sido inventariada y catalogada durante tres años (2016 a 2019) proceso que ha generado la confección de un catálogo completo de los materiales que conserva. Para las labores de catalogación se siguieron las indicaciones amablemente suministradas por el Servicio de Documentación Geográfica y de Biblioteca del Instituto Geográfico Nacional (IGN) dependiente del Ministerio de Transportes, Movilidad y Agenda Urbana, con quien primeramente se contactó para llevar a cabo el cometido. ${ }^{7}$

En cuanto al método, se ha aplicado la metodología expuesta y desarrollada en la obra de Líter Mayayo y García Calatayud. ${ }^{8}$ Al no tratarse de una cartoteca especialmente numerosa en lo referente al número total de piezas, se optó por diseñar una base de datos utilizando el software Access que permitiese una gestión catalográfica óptima de la colección. Para ello, fue preciso la descripción y el diseño de la ficha-tipo con los campos constituyentes de dicha base, los cuales se articularon en tres bloques (tabla 1).

Tabla 1. Diseño de la base de datos

\begin{tabular}{|l|l|l|}
\hline $\begin{array}{c}\text { Campos de información } \\
\text { identificativa de la pieza }\end{array}$ & \multicolumn{1}{|c|}{$\begin{array}{c}\text { Campos de información } \\
\text { descriptiva del material }\end{array}$} & $\begin{array}{c}\text { Campos de información } \\
\text { gráfica }\end{array}$ \\
\hline & $\begin{array}{l}\text { - Punto de acceso } \\
\text { - Título y mención de } \\
\text { responsabilidad } \\
\text { - Edición }\end{array}$ & \\
- Número & $\begin{array}{l}\text { - Datos matemáticos } \\
\text { - Publicación y/o distribución } \\
\text { - Regnatura }\end{array}$ & $\begin{array}{l}\text { - Imágenes y } \\
\text { fotografías del } \\
\text { documento }\end{array}$ \\
& $\begin{array}{l}\text { - Descripción física } \\
\text { - Serie }\end{array}$ & \\
\hline & $\begin{array}{l}\text { - Número normalizado } \\
\text { - Notas }\end{array}$ & \\
\hline
\end{tabular}

Fuente: elaboración propia.

\footnotetext{
${ }^{7}$ Agradecemos también la disponibilidad de los fondos del IGN cuya cartoteca se puede consultar en https://www.ign.es/web/catalogo-cartoteca/ y de los recursos del Centro Nacional de Información Geográfica disponibles en https://centrodedescargas.cnig.es/CentroDescargas/index.jsp, (consultadas el 15-09-2021).

${ }^{8}$ Carmen Líter Mayayo y Carmen García Calatayud. Materiales cartográficos: manual de catalogación (Madrid: Arco Libros, 1999).
} 
El primero recogía la información de campos referida a documentación general básica para la identificación y el registro de la pieza como un número correlativo, la signatura y el número de registro. El segundo comprendía aspectos meramente descriptivos como el punto de acceso, el título y la mención de responsabilidad, la publicación y distribución, y una descripción física, entre otros. El tercero se componía del registro de imágenes y fotografías que ilustran el objeto inventariado en sí. La utilización de este software permite, entre otras muchas opciones, la consulta de información contenida en la base de datos mediante la generación de informes personalizables en varios formatos.

Todo el material se ha conservado, cuando el tamaño lo ha permitido, en los correspondientes muebles habilitados para ello (planeros). Sin embargo, cuando sus dimensiones no permitían esta opción, se ha mantenido en sus cilindros de cartón originales. Cuando estos tampoco se habían conservado, se ha optado por el uso del embalaje con papel libre de ácidos, como medida transitoria, hasta la aplicación definitiva de las adecuadas medidas de conservación.

El conjunto de la cartoteca consta de 234 mapas, tanto murales como de mesa, de muy variada procedencia y finalidad, y 6 esferas, una de ellas armilar. Lo más destacado es la cronología de algunas de sus piezas, ya que se sitúan a finales del siglo XIX (circa 1885) y se extiende hasta el siglo XXI (2009).

\section{LA CONFIGURACIÓN DE LA CARTOTECA DEL CENTRO}

La constitución de la cartoteca hunde sus raíces a mediados del siglo XIX, concretamente con la aparición de la Real Orden de 1844. ${ }^{9} \mathrm{Al}$ año siguiente, comienza a configurarse el equipamiento básico del centro siguiendo las indicaciones del Reglamento del Plan de Estudios emitido por el Ministerio de la Gobernación. ${ }^{10}$ En este documento, concretamente en el título VI, se listan los medios materiales de instrucción

\footnotetext{
${ }^{9}$ Ministerio de la Gobernación, «Real Orden creando en la capital de la provincia de Cuenca un instituto de segunda enseñanza», Boletín Oficial de la Instrucción Pública, 13 (1844): 636.

${ }_{10}$ Víctor Guijarro Mora. Artefactos y acción educativa. La cultura del objeto científico en la enseñanza secundaria en España (1845-1930) (Madrid: Dykinson y Universidad Carlos III, 2018). En las páginas 56 y siguientes se realiza un análisis exhaustivo de este documento administrativo. http://hdl.handle. net/10016/27200 (consultado el 02-06-2020).
} 
que deberían encontrarse en todos los establecimientos públicos de enseñanza. Junto a la habilitación adecuada de las aulas y los auditorios para las correspondientes cátedras, los institutos de segunda enseñanza y las facultades de Filosofía debían contar además con:

$1 .^{\circ}$ Los instrumentos de matemáticas necesarios para la enseñanza de estas ciencias, como igualmente una colección de sólidos para las demostraciones de geometría. $2 .^{\circ}$ Los globos, mapas y demás que requiere la enseñanza de la geografía. $3 .^{\circ}$ Los cuadros sinópticos que faciliten la de la historia. [...]. 5. ${ }^{\circ}$ Un gabinete de física con todos los aparatos que exige la enseñanza elemental de esta ciencia $[\ldots] .8 .^{\circ}$ Una colección clasificada de mineralogía [...]. 10. ${ }^{\circ}$ Un jardín botánico y un herbario dispuesto metódicamente. ${ }^{11}$

Asimismo, desde la Dirección de Instrucción Pública, llegará a los centros, una misiva que urgía a abastecer con materiales científicos los institutos de instrucción pública para la explicación de las ciencias físicas y naturales. ${ }^{12}$ Con esta provisión, se podían impartir mejor las clases con el pertinente apoyo del instrumental práctico ${ }^{13}$ y no solo con explicaciones meramente verbales. Para cumplir con estas instrucciones, el centro recién creado hará acopio, progresivamente, de los recursos materiales imprescindibles entre los que cabría destacar una pequeña colección de minerales, algunos aparatos de física, varios animales naturalizados, un herbario, y varios «mapas, esferas, para el estudio de la geografía». ${ }^{14}$

Con el paso del tiempo y con la financiación suficiente, el Instituto Provincial, dependiente de la Universidad Central, aumentó considerablemente el elenco de objetos en los siguientes cursos. De hecho, en el año 1861-1862, la Memoria del Instituto registra cuatro esferas (una armilar), siete mapas murales muy homogéneos en su composición, tres mapas (uno general de España y dos en relieve), una colección de cartas

\footnotetext{
${ }_{11}$ Ministerio de la Gobernación, «Real Decreto Reglamento para la ejecución del Plan de Estudios», Gaceta de Madrid, (1845), nº. 4056-4072, 22 de octubre, artículo 173.

12 Ministerio de la Gobernación, «Boletín Oficial de Instrucción Pública», 19, (1846): 545.

13 Víctor Guijarro Mora. Artefactos y acción educativa. La cultura del objeto científico en la enseñanza secundaria en España (1845-1930) (Madrid: Dykinson y Universidad Carlos III, 2018), 62. http://hdl. handle.net/10016/27200 (consultado el 02-06-2020).

${ }^{14}$ Bernardo Gómez de Segura. Memoria... acerca del estado del Instituto de 2. ${ }^{a}$ Enseñanza de Cuenca leída el día 16 de septiembre de 1859 (Cuenca: Imprenta Pedro Mariana, 1859), 8.
} 
geográficas de las diversas provincias y colonias españolas, y varios cuadros de temática variada (cosmografía general, movimientos aparentes del sol, fases de la luna, altura de las montañas y longitud de los ríos, y tipos de razas del género humano), entre los materiales adquiridos..$^{15} \mathrm{La}$ tendencia incremental de compras de instrumentos didácticos se mantuvo en los cursos sucesivos, con adquisiciones para el gabinete y la cátedra de Geografía. Fruto de ello serán las nuevas incorporaciones, como un mapa de España de Francisco Coello (1862); varias cartas murales del Imperio Romano y Grecia (1864); un atlas de Geografía de la Edad Media y Moderna, y un mapa mural de España y Portugal (1864), entre otros. Además de los productos recién adquiridos, también se tomarán medidas destinadas a la conservación de estos, como la fijación de «medias cañas y ribeteo de cintas» ${ }^{16}$ en los mapas, para evitar su deterioro.

El siguiente decenio (1870-1880) traerá novedades a la cartoteca tras el impacto de la contienda bélica de 1874, que destruyó buena parte del inventario anterior. Pasado el episodio, en el curso 1876-1877, se obtuvieron dos esferas (celeste y armilar), un mapa de España (G. Pfeiffer) y un atlas de las provincias españolas publicado por D. M. Grilo, ${ }^{17}$ de manera que se alcanzasen progresivamente los niveles mínimos exigidos para la enseñanza adecuada de la disciplina. Un par de años más tarde, el listado de instrumentos didácticos del gabinete de Geografía totalizaba dieciocho elementos, incluyendo globos celestes y terrestres, mapas (varios de Dufour) y algunos atlas. ${ }^{18}$ Estos primeros mapas de Henri Auguste Dufour, ${ }^{19}$ por cronología, podrían tratarse de producciones de mapas y atlas de corte histórico. ${ }^{20}$

\footnotetext{
15 Bernardo Gómez de Segura. Memoria acerca del estado del Instituto de 2. ${ }^{a}$ Enseñanza de Cuenca leída el día 16 de septiembre de 1861 (Cuenca: Imprenta Pedro Mariana, 1861), 29.

16 Bernardo Gómez de Segura. Memoria acerca del estado del Instituto de 2. ${ }^{a}$ Enseñanza de Cuenca leída el día 16 de septiembre de 1863 (Cuenca: Imprenta Pedro Mariana, 1863), 23.

${ }_{17}$ Mariano Sánchez Almonacid. Memoria acerca del estado del Instituto de 2. ${ }^{a}$ Enseñanza de Cuenca leída el día 1 de octubre de 1877 (Cuenca: Imprenta Manuel Mariana, 1877), 1-42.

18 Ruperto Giménez de Oca. Memoria acerca del estado del Instituto de 2. ${ }^{a}$ Enseñanza de Cuenca (1878-1879) (Cuenca: Imprenta Provincial, 1880), 1-61.

19 En la Biblioteca Nacional se pueden ver otros ejemplos atribuidos a este editor cartográfico: http:// bdh.bne.es (consultado el 11-06-2020).

${ }_{20}$ Manuel Santirso Rodríguez, «Los atlas históricos en la España contemporánea: una exploración», Scripta Nova. Revista Electrónica de Geografía y Ciencias Sociales, XV (365). http://www.ub.edu/geocrit/sn/sn-365.htm (consultado el 02-06-2020)
} 
La colección comienza a afianzarse con adquisiciones posteriores como un curioso selenurio de Tomás Escriche ${ }^{21}$ comprado como material científico en el curso 1881-1882.22 Un año después, el inventario se ensancha con un elenco de mapas murales elaborados por Meissas y Michelot relativos a Europa, África y América; un mapa provincial de Domínguez Alonso (curso 1884-1885); un planetario de estrellas dentro de un globo de cristal de $50 \mathrm{~cm}$; una colección de diez tablas explicativas del sistema planetario, y un mapa de España y Portugal de dieciséis hojas en tela de E. Paluzie. ${ }^{23}$ Como artefacto curioso, el centro pudo adquirir una máquina cosmográfica de León Girod y, casi una década después, en el curso 1896-1897 se aumentó la cartoteca con la colección de mapas mudos de la editorial Paluzie, ${ }^{24}$ especializada en mapas-mundi y mapas generales. Esta empresa, afincada en Barcelona, editaba algunas de las pocas cartas didácticas de producción española en esa fecha. ${ }^{25}$

A pesar del incremento considerable y de los esfuerzos económicos del momento, el patrimonio cartográfico escolar del Instituto se mostraba escaso en conjunto. En general, la asignatura de Geografía venía sufriendo un notable atraso en lo referente a materiales, hecho recogido y expresado en diversos foros ${ }^{26}$ por la Sociedad Geográfica de Madrid y que se traducía, indirectamente, en una acusada ignorancia nacional hacia esta disciplina hasta tal punto que:

\footnotetext{
21 Ángel Zamoro Madera. D. Tomás Escriche y Mieg, 1844-1935: profesor de segunda enseñanza (18691918) (Badajoz: Diputación de Badajoz, 2015).

${ }^{22}$ Ramón Torres. Memoria acerca del estado del Instituto de 2. ${ }^{a}$ Enseñanza de Cuenca (1881-1882) (Cuenca: Imprenta Provincial, 1883), 1-58.

${ }^{23}$ Luis Méndez Soret. Memoria acerca del estado del Instituto de 2. ${ }^{a}$ Enseñanza de Cuenca (1885-1886) (Cuenca: Imprenta Provincial, 1887), 53.

${ }^{24}$ Jaime Fernández-Castañeda y Valle. Memoria acerca del estado del Instituto de $2 .{ }^{a}$ Enseñanza de Cuenca leída en la apertura del curso 1896 á 97) (Cuenca: Imprenta de Celedonio León, 1897), 46.

${ }^{25}$ Leoncio López-Ocón, «La renovación de la enseñanza de la geografía en las aulas de bachillerato en los primeros años del siglo XX» en Aulas modernas. Nuevas perspectivas sobre las reformas de la enseñanza secundaria en la época de la JAE (1907-1939), Leoncio López-Ocón (ed.) (Madrid: Universidad Carlos III, 2014a), 91. http://hdl.handle.net/10016/19883 (consultado el 02-06-2020).

26 Joaquín Bosque Maurel, «Odón de Buen (1863-1945)», Boletín de la Real Sociedad Geográfica, 139140, CXXXIX-CXL, (2003): 267-292.

https://realsociedadgeografica.com/wp-content/uploads/2018/02/BOLETIN-RSG-2003-2004-CXXXIX-CXL.pdf (consultado el 03-06-2020)
} 
Es evidente, por el contrario, nuestra ignorancia nacional en punto a Geografía: ni los mismos encargados de enseñarla, en su inmensa mayoría, la saben; pues a pesar de ser muy pundonorosos y muy competentes en otras materias, no han podido sustraerse al general atraso de la ciencia geográfica entre nosotros, y no se han hecho cargo de unos estudios que ni figuraban como asignatura en la carrera de Filosofía y Letras, ni se exigían como prueba en las oposiciones, donde predominaba el examen Historia. ${ }^{27}$

Esta misma idea latía inherentemente en los mensajes pronunciados, en una conferencia sobre la enseñanza de la ciencia geográfica, por dos auténticos conocedores de la realidad del momento, quienes mostraban sus quejas ardientemente ante tal circunstancia. ${ }^{28}$ Se trataba de Rafael Álvarez Sereix y Leopoldo Pedreira Taibo. En palabras de este último, profesor y catedrático numerario de Geografía del instituto de Cuenca entre 1899 y 1906, ${ }^{29}$ y por lo tanto, experto de los fondos cartográficos del centro, la situación latente de crisis evidencia que: «acerca de esta falta de material nada más elocuente que lo que ha podido comprobar el Claustro del Instituto de Cuenca; se acordó la compra de un mapa particular de cada una de las naciones de Europa y se acordó la adquisición en favor de editores españoles». ${ }^{30}$ Pero la petición de material realizada no pudo ser satisfecha por las editoriales nacionales de manera que «fue necesario acudir a Kiepert, de Berlín, resultando caros por el cambio, transporte y... jaduana!; pero como aquí no había lo que se solicitaba, se redujo el pedido a condiciones mínimas, y la clase quedó sin material». ${ }^{31}$

La solicitud de una batería de mapas de cada una de las naciones de Europa respondía a la necesidad imperante de desarrollar una buena clase de Geografía Universal, contando con una completa colección de

\footnotetext{
27 Rafael Álvarez Sereix y Leopoldo Pedreira Taibo, «La enseñanza de la geografía. Lo que es y lo que debiera ser en España», Boletín de La Real Sociedad Geográfica, XLV, (1903): 269.

28 Agustín Hernando, «La educación de un geógrafo. Propuestas históricas de planes de estudio de Geografía en España», Revista de Geografía, XXIX, (1995): 49.

${ }^{29}$ Lorena Domínguez Mallo, «Leopoldo Pedreira Taibo, intuición historiográfica e virulencia crítica», Galicia21 Journal of Contemporary Galician Studies, D, (2012): 29.

https://realsociedadgeografica.com/wp-content/uploads/2018/02/BOLETIN-RSG-2003-2004-CXXXIX-CXL.pdf (consultado el 06-06-2020).

30 Rafael Álvarez Sereix y Leopoldo Pedreira Taibo, «La enseñanza de la geografía», 272.

31 Rafael Álvarez Sereix y Leopoldo Pedreira Taibo, «La enseñanza de la geografía», 272.
} 
cartas que mostrasen los principales estados europeos, pero también un buen elenco de otros mapas generales modernos. En cierta medida, este aspecto recogía los escasos recursos cartográficos presentes en los centros de enseñanza, debido en parte a las pérdidas originadas por vicisitudes de diversa índole (deterioros, saqueos, etc.), pero también al escaso interés despertado por los propios docentes en la enseñanza de la disciplina vista en este momento como regeneración de la enseñanza de la patria. ${ }^{32}$

El afán de contar con una potente cartoteca palpitaba también en las pretensiones renovadoras de Rafael Ballester y Castell, quien defendía, entre sus principios metodológicos innovadores, que los alumnos debían leer un mapa y trabajar adecuadamente un plano al margen de poder listar, de memoria, mares europeos, cabos o islas. ${ }^{33} \mathrm{El}$ panorama educativo de la época apuntaba hacia un aprendizaje basado en una retahíla de productos, una enumeración de ríos, de montañas, de ciudades y de estados. No se trataba de «inutilizar» esos conocimientos, sino que fueran la antesala de una verdadera enseñanza de la Geografía. Esta incipiente idea ha sido recuperada posteriormente por instituciones internacionales con el fin de conseguir una auténtica educación geográfica. ${ }^{34}$

Sin embargo, estos planteamientos topaban con una realidad latente en los centros educativos, donde permanecía viva la creencia de que la cátedra de Geografía no precisaba de materiales de carácter científico, salvo las colecciones básicas y ordinarias compuestas por cualquier tipo de mapas y globos sin condiciones pedagógicas apropiadas. Esta postura se refrendaba aún más al considerar los artefactos geográficos y las cartas murales como material pedagógico intermedio, circunstancia que se venía debatiendo desde hacía tiempo. Como referencias anteriores de la cuestión, buena parte de ellas ponían en entredicho la utilización de recursos a la hora de la praxis en el aula. Sirva de ejemplo, la voz acreditada de Rousseau, quien defendía que se enseñase el objeto mismo sin

\footnotetext{
32 Rafael Álvarez Sereix y Leopoldo Pedreira Taibo, «La enseñanza de la geografía», 272.

33 Rafael Ballester y Castell, Investigaciones sobre metodología geográfica (Madrid: Imprenta del Patronado de Huérfano de Administración Militar y Universidad Central de Madrid, 1908).

${ }_{34}$ Organización de las Naciones Unidades para la Educación, la Ciencia y la Cultura (UNESCO), Método para la enseñanza de la Geografía (Barcelona: Teide, 1966).
} 
precisar herramientas «globos, esferas y mapas»;35 la de Comenio, que consideraba que en el aprendizaje de los rudimentos de la Geografía lo esencial era «empezar a aprender qué es un monte, un valle, un campo, el río, la aldea, la fortaleza, la ciudad, conforme a la oportunidad que para ello ofrezca el lugar en que se educan», 36 y la de Levasseur, que apostaba por la experiencia directa sin intermediarios posibles.

Visto desde esta postura, el análisis con la realidad próxima de cada niño conformaría la base sólida de la educación geográfica desarrollándose un auténtico sentido geográfico aspirando a imaginar la realidad que no veía directamente, para lo cual sí se precisaba la utilización de herramientas que sirvieran de "puente». Una vez obtenida la imagen, ya se podría recurrir al mapa, entendiéndolo como un signo formal en el que el alumno profundizase el significado que contenía en sí mismo empezando a conocerlo mediante el relieve ${ }^{37}$ y sin olvidar que su uso se encuentra al servicio de la Geografía, de la formación geográfica del alumnado y de la comprensión de las peculiaridades del espacio y del territorio. ${ }^{38}$

Por tanto, el material de enseñanza en los distintos niveles educativos se hacía perentorio para el óptimo desarrollo de las clases, como defendían los regeneracionistas del momento, pero el estado en que se encontraba era capital porque «en la mayoría de los casos en que el material se solicita y quiere aplicarse, no es el adecuado, y en su empleo resulta, más que inútil, contraproducente». ${ }^{39}$ Se trasluce aquí la cuestión del estado en que se encontraba el material didáctico de los recursos en los gabinetes de Geografía, tema capital para una enseñanza adecuada. De ello, se hacía eco Ballester y Castell: su afán reformador tanto de la cultura como de la educación ${ }^{40}$ en general convergía con las propuestas

\footnotetext{
35 Domingo Barnés, "El material de enseñanza», Boletín de la Institución Libre de Enseñanza, XLI, n. ${ }^{\circ} 688$ (1917): 201.

36 Amós Comenio, Didáctica Magna (México: Editorial Porrúa, 1998), 110.

37 Barnés, «El material de enseñanza», 202.

${ }^{38}$ María Francisca Orellana Álvarez, «El mapa y la formación del profesorado. Aportaciones sobre la cartografía en revistas y sugerencias bibliográficas», Didáctica Geográfica, 5, (2002), 11-41.

39 Barnés, «El material de enseñanza», 199.

40 Rafael Valls Montés, «La institución libre de enseñanza y la educación histórica: Rafael Ballester y la renovación historiográfica y didáctica españoles de inicios del siglo XX», Historia de la Educación: Revista Interuniversitaria, 31, (2012): 234.
} 
defendidas, desde principios de siglo, por los principales ideólogos de la Institución Libre de Enseñanza. Este profesor contactó con varios catedráticos de Geografía de institutos para analizar sus inventarios. ${ }^{41}$ Solicitaba el envío de información tanto del estado de los materiales de estos centros como de la utilización de los métodos que empleaban para su enseñanza en las aulas. ${ }^{42}$ La consulta se saldó con respuestas de varios catedráticos siendo una de las más elocuentes la del titular de $\mathrm{La}$ Coruña, que expresaba que «el material no pasa de regularcito..., y gracias, pues lo consignado para gastos de esta naturaleza es una insignificancia...en cuanto al método, el libro es el auxiliar, la explicación y el mapa lo esencial».43

Años después, el debate seguía abierto respecto a la enseñanza de la disciplina y se continuaba reflexionando sobre los programas, los contenidos y la implantación de metodologías, en este caso, en la escuela primaria. ${ }^{44}$

Conocedor de estas realidades, Leopoldo Pedreira reivindicará la necesidad de una financiación adecuada para la compra de cartas cartográficas con las que se desarrollen auténticas clases de geografía conociendo los últimos rincones del mundo. De hecho, él sabía que:

En el Instituto de Cuenca, por ejemplo, no hubo ningún mapa de la llamada Oceanía hasta que el actual catedrático hizo traer de Berlín una carta muda de Geografía física de Australia y Polinesia, y no pudo completar la colección de esta parte del mundo por no existir bastantes fondos para material en el establecimiento. ${ }^{45}$

Esta carencia ostensible fue subsanada con la compra del mapa de Oceanía de la casa Kiepert que él mismo ejecutó y que conforma el mapa más antiguo conservado en el repertorio cartográfico del centro.

\footnotetext{
${ }_{41}$ Álvarez Sereix y Pedreira Taibo, «La enseñanza de la geografía», 270. Se recogen los institutos de Cádiz, Sevilla, Córdoba, Orense, La Coruña, Lugo, Pontevedra, Lérida, Gerona, Barcelona, Toledo, Segovia y Ciudad Real.

${ }^{42}$ Valls Montés, «La institución libre de enseñanza y la educación histórica», 231-256.

43 Álvarez Sereix y Pedreira Taibo, «La enseñanza de la geografía», 270.

44 Ángel Do Rego, «Nociones para un programa de la enseñanza de la geografía en la escuela primaria», Boletín de la Institución Libre de Enseñanza, XL (675), (1916), 165-168.

45 Álvarez Sereix y Pedreira Taibo, «La enseñanza de la geografía», 274.
} 
Hasta la década de los treinta del siglo XX, el inventario del gabinete manifestó un incremento progresivo. En el curso 1909-1910, la cátedra de Geografía recogía trece objetos, entre esferas (terrestre y celeste), dos aparatos para la demostración de eclipses lunares y solares, otro para el aprendizaje del movimiento de los planetas, una linterna de proyección, un listado de vistas (Grecia, España, civilización árabe), doce mapas murales, dos pasavistas y un mapa mudo apizarrado de España. ${ }^{46}$ A lo largo del siguiente decenio, en el curso 1921-1922 se registran varios mapas murales (África, América del Norte, América del Sur, Asia, Australia y España $)^{47}$ y en el de $1925-1926$, se adquieren un par de mapas en relieve, uno de España y otro de la provincia de Cuenca. ${ }^{48}$

\section{COMPOSICIÓN DE LA CARTOTECA}

\section{Fases cronológicas}

En clave evolutiva, se podrían establecer varios períodos para un análisis en detalle de la colección (figura 1). Por un lado, las producciones fechadas hasta la década de los años treinta del siglo XX apenas suman 38 cartas (16\% sobre el total) concentrándose especialmente en las adquisiciones obtenidas en los años treinta. Por otro, en el intervalo de años cuarenta y cincuenta se compraron un buen número de mapas (83) representando el 36\%, hito temporal coincidente con la publicación de la mayoría de las hojas del Mapa Topográfico Nacional (MTN) de que dispone el instituto: las que comprenden la provincia de Cuenca. Y, finalmente, desde los años sesenta hasta el momento actual, se suman 111 cartografías (casi un 50\%), con la adquisición, ya generalizada y estable, de veinte mapas o más por década, superando las cifras del primer cuarto del siglo $\mathrm{XX}$.

\footnotetext{
${ }^{46}$ Joaquín López Barrera. Memoria acerca del estado del Instituto General y Técnico de Cuenca durante el curso de 1910 a 1911. (Cuenca: Imprenta y librería de Celedonio León, 1911), 1-82.

47 Ángel Martínez y Martínez. Memoria acerca del estado del Instituto General y Técnico de Cuenca durante el curso de 1921 a 1922. (Cuenca: Imprenta y librería de Viuda de Celedonio León, 1923), 36.

${ }^{48}$ Millán Catalina Martínez. Memoria acerca del estado del Instituto Nacional de $2 .{ }^{a}$ Enseñanza de Cuenca durante el curso de 1926 a 1927. (Cuenca: Imprenta y librería de Viuda de Celedonio León, 1927), 1-55.
} 
Figura 1. Evolución cronológica del número total de mapas por años de edición

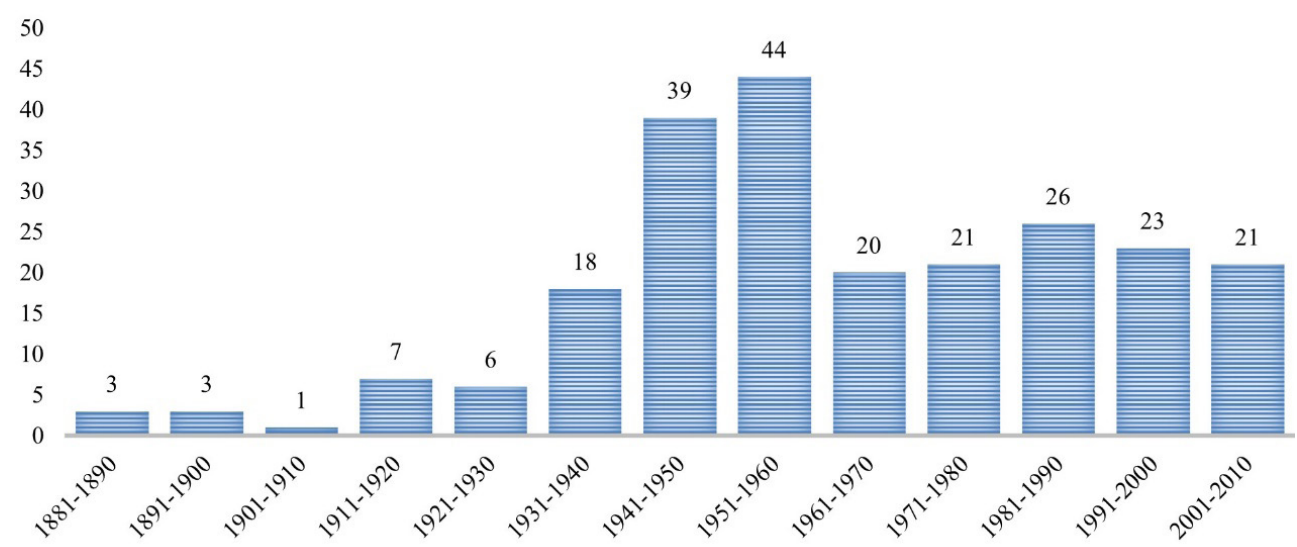

Fuente: elaboración propia.

\section{Aproximación a las editoriales y productoras}

En relación con las casas cartográficas, el análisis en detalle muestra la preeminencia de editoras con sede en el continente europeo, un 98,7\%, frente a las procedentes de otros territorios (Argentina) y las que no se ha podido consignar su procedencia, que suponen un 1,3\% del total.

Dentro de las producciones europeas, más del $80 \%$ corresponde a cartografías de origen español (184 mapas), con especial relevancia de las editadas en el período más reciente; les siguen las producciones italianas, con 13 mapas y un 5,7\%; después las alemanas, con 12 cartografías y un $5,2 \%$; los mapas franceses con diez cartas geográficas y un valor del 4,3\%, y, finalmente, Austria, con nueve mapas y un 3,9\% sobre el total de mapas del continente europeo. Meramente testimonial, el único ejemplar editado en Suiza representa un 0,43\%.

Los mapas alemanes se adquieren hasta 1935. Entre ellos figuran los más antiguos de la cartoteca: los editados por la casa berlinesa Dietrich Reimer y Ernst Vohsen. Solo un ejemplar de Westermann y otros dos, geológicos, en papel y editados por la UNESCO, son posteriores a esta fecha.

Tras la Guerra Civil se constata el abandono del aprovisionamiento de mapas procedentes de Alemania y Francia. El lugar que estos dos 
países detentaban hasta la posguerra española fue ocupado por otros dos europeos: las ediciones italianas de la casa Vallardi y las austríacas de Freytag \& Berndt, ambas de la década de los cincuenta.

¿Por qué se produce este reemplazo entre los proveedores cartográficos foráneos? Sin duda alguna, por la producción, por estas dos últimas editoriales, de ediciones en castellano, lo que permitió que la distribuidora «Cultura Eimler, Basanta, Haase» los incluyera en su catálogo, en consonancia con el nacionalismo imperante entonces en España. A este respecto, es sintomático que los tres ejemplares de Freytag \& Berndt impresos en alemán que se conservan en el centro, sean anteriores a la Guerra Civil.

Acorde con estas orientaciones políticas que se traslucen en el equipamiento docente, a partir de los años sesenta, las editoriales españolas monopolizarán la dotación cartográfica de los centros de enseñanza desapareciendo prácticamente las producciones extranjeras.

\section{Principales editoriales españolas}

En un análisis más pormenorizado por casas de fabricación, las reproducciones originarias de la península ibérica se focalizan en dos frentes. Por un lado, las editoriales catalanas: Dalmau, Carles y Plá; la imprenta Elzeviriana; la librería Camí; Teide; Seix Barral y Vicens Vives, y, por otro, las madrileñas: Aguilar y el Instituto Geográfico y Catastral. Los dos grandes proveedores de materiales al centro son: el Instituto Geográfico y Catastral ${ }^{49}(37 \%)$ y la casa barcelonesa Vicens Vives $(21,7 \%)$. El resto de las aportaciones muestran valores porcentuales comparativamente más modestos, como los mapas de otros organismos oficiales $(9,8 \%)$; las publicaciones de otras editoriales privadas $(9,8 \%)$; y la editorial Aguilar (9\%) (figura 2). De las producciones españolas que se conservan, la más antigua corresponde al mapa de Oceanía de la casa barcelonesa Seix y Barral, editado aproximadamente entre 1922 y 1929, seguido de los producidos por la Imprenta Elzeviriana y Librería Camí, publicados entre 1935 y 1936.

\footnotetext{
${ }^{49}$ La práctica totalidad de los fondos procedentes de este organismo que conserva el IES Alfonso VIII proceden de la época en que se denominaba Instituto Geográfico y Catastral (entre 1925 y 1977), por eso se mantiene esta denominación entre los demás nombres del IGN a lo largo de su historia.
} 
Figura 2. Representatividad porcentual por casas productoras españolas

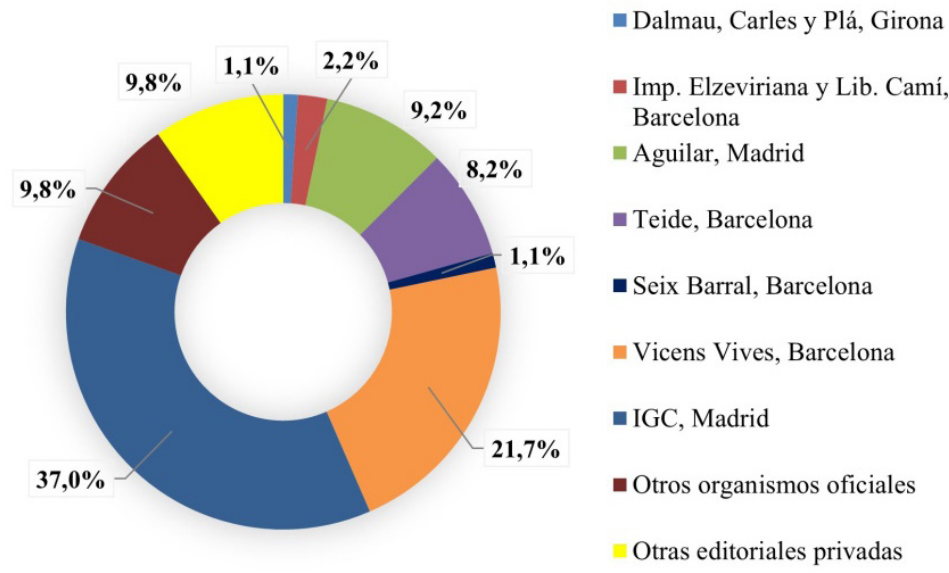

Fuente: elaboración propia.

En el caso del Instituto Geográfico y Catastral, se han catalogado 60 ejemplares de las hojas del MTN correspondientes a 48 de las 50 hojas que comprende la provincia de Cuenca, faltando solo dos: la n. ${ }^{\circ} 537$ (Auñón) y la n. ${ }^{\circ} 714$ (Campo de Criptana). La mayoría de ellas pertenece a la primera edición (treinta y nueve hojas) y el resto a la segunda, de ahí que el abanico de fechas se sitúe entre 1919 y 1982.50 La Administración General del Estado llevó a cabo una donación al centro de 39 hojas del mapa en el año 1963. En conjunto, las producciones procedentes de este organismo estatal suponen el 37\% del total de las editoriales españolas.

Cabe decir que el MTN, como herramienta didáctica, ha sido muy utilizado y explotado a distintos niveles educativos, como recoge el compendio elaborado por Puyol y Estébanez ${ }^{51}$ para trabajar este tipo de cartografía. No en vano, la práctica docente en las aulas se ha apoyado, con frecuencia, en la utilización de este mapa institucional como instrumento esencial. ${ }^{52}$ La apuesta por parte del organismo cartográfico se ha ido

\footnotetext{
${ }_{50}$ Todas las hojas, en sus diferentes ediciones, se pueden obtener en el Centro de Descargas del CNIG: https://centrodedescargas.cnig.es/CentroDescargas/index.jsp, (consultado el 15-09-2020).

${ }_{51}$ Rafael Puyol Antolín y José Estébanez Álvarez, Análisis e interpretación del mapa topográfico (Madrid: Tebar Flores, 1976), 1-88.

${ }_{52}$ Fernando Aranaz del Río, Tu amigo el mapa (Madrid: Instituto Geográfico Nacional, 2010), 1-158.
} 
consolidando con la elaboración de materiales y recursos pedagógicos destinados a las distintas etapas educativas, ${ }^{53}$ incluyendo versiones digitales actualizadas del mismo lo que supone, sin duda alguna, una reducción considerable del uso de mapas en formato papel.

Las producciones catalanas de Vicens Vives se sitúan en segundo lugar respecto al total de piezas catalogadas. El propio Jaume Vicens Vives mostró interés en todo momento porque sus producciones contuvieran aspectos de geografía, historia y cartografía, estando estrechamente interrelacionados entre sí. De hecho, dos podrían ser las claves que marcaron todo su afán en la producción cartográfica, como recoge Villanova: por un lado, «la utilidad e importancia que otorgaba a la geopolítica — de la que el mapa es componente indisoluble—»y por otro, «su enorme vocación didáctica». ${ }^{44}$ Sus posturas sobre geopolítica y, en concreto, sobre la teoría del «espacio vital» propias del momento e imbuidas de las relaciones diplomáticas internacionales, se plasmaron en la publicación del semanario Destino a finales de la tercera década del siglo XX. ${ }^{55}$

La editorial Vicens Vives, con sede en Barcelona, será fundada por Roser Rahola, viuda de Jaume. ${ }^{56}$ En lo que a producciones en el centro educativo se refiere aporta cuarenta mapas $(21,7 \%)$ de los cuales un $50 \%$ corresponden a la serie Mapas murales históricos compuesta por un total de dieciocho representaciones. Se trata de una casa editorial con una abundante producción en cartografía escolar desde bien entrada la década de los años setenta hasta fechas actuales..$^{57}$ Sus cartografías eran realizadas por el Instituto Cartográfico Latino, fundado en 1948 y reconocido oficialmente por el Ministerio de Educación y Ciencia en 1967. En 2016 fue absorbido por la editorial.

\footnotetext{
53 Ana Velasco Tirado, «Recursos educativos de cartografía, geografía y ciencias de la Tierra del Instituto Geográfico Nacional» en La reconfiguración del medio rural en la sociedad de la información, Xosé Carlos Maciá Arce, Francisco Xosé Armas Quintá y Francisco Rodríguez Lestegás (coords.) (Santiago de Compostela: Grupo de Didáctica de la Geografía de la AGE y Andavira editora, 2019), 467-480.

54 José Luis Villanova, «La cartografía en la obra de Jaume Vicens Vives», Estudios Geográficos, 59 (1988): 714.

55 Jaume Vicens Vives, «Teoría del “Espacio vital” ", Destino, segunda época, 104, (1939), 4.

56 José Martín López, Cartógrafos españoles (Madrid: Centro Nacional de Información Geográfica, 2017), 306.

57 Santirso Rodríguez, «Los atlas históricos en la España contemporánea».
} 
La casa madrileña Aguilar fue abastecedora de mapas para las aulas durante los años sesenta y setenta del siglo pasado y supone un 9,2\% del total de las originadas en el territorio español. Los ejemplares conservados en el instituto, 17, algunos de la Península Ibérica y otros de distintos continentes, forman parte de la serie Mapas murales Aguilar, editados entre las fechas de 1958 y 1969. Desde el punto de vista estilístico, se trata de cartas geográficas dominadas por la claridad, la buena visibilidad y la legibilidad de la toponimia.

Del proveedor catalán Teide, fundado en 1942 como sociedad anónima $^{58}$ se conservan quince ejemplares $(8,1 \%)$ producidos en el bienio 1977-1978. Sus promotores fueron Jaume Vicens Vives y su cuñado Frederic Rahola.$^{59}$ La editorial apostaba por la docencia y la edición de obras didácticas. ${ }^{60}$ Las cartografías conservadas en el instituto pertenecen a la serie Mapas murales Teide, acreditadas por el Instituto Geográfico de Agostini, procedente de la ciudad de Novara (Italia). De hecho, el estallido de esta editorial marcará un auténtico punto de inflexión en la producción de materiales de enseñanza, especialmente en la vertiente de renovación de elementos gráficos. ${ }^{61}$ En general, las dos editoriales catalanas editaron sus mapas con tonos más vivos y mayor abundancia de toponimia, sin perder por ello la claridad inherente a todo material pedagógico.

Los mapas procedentes de otros organismos e instituciones representan el 9,7\%. Destacan algunos ejemplares interesantes, como el mapa geológico de España de 1932, editado por el Instituto Geológico y Minero de España; las cartas geográficas de colonias españolas en África, publicadas por la Dirección General de Marruecos y Colonias y por el Instituto de Estudios Africanos (1951-1952); las cartografías agrícolas, y otras de temáticas diversas.

\footnotetext{
${ }^{58}$ Santirso Rodríguez, «Los atlas históricos en la España contemporánea».

59 Villanova, «La cartografía en la obra de Jaume Vicens Vives», 718.

${ }^{60}$ Francisco Javier Merchán Iglesias, Olga Duarte-Piña y Nicolás de Alba Fernández, «La enseñanza de la Historia como formación para la participación ciudadana» en Educar para la participación ciudadana en la enseñanza de las Ciencias Sociales, Nicolás de Alba Fernández, Francisco F. García-Pérez y Antoni Santisteban Fernández (coord.) (Sevilla: Asociación de Profesores de Didáctica de las Ciencias Sociales y Díada, 2012), 193-202.

${ }^{61}$ Anna Fabre y José Luis Villanova, «Jaume Vicens Vives.1910-1960», Geographers. Bibliographical Studies, 17 (1997): 62-105.
} 
Los mapas apizarrados fueron corrientes en la primera mitad del siglo pasado y, de hecho, otros institutos conservan varios ejemplares. Sin embargo, el instituto Alfonso VIII custodia solo uno: el de América del Sur y realizado en los años treinta por la editorial Dalmau Carles y Plá.62 El germen de esta empresa se sitúa en la figura de Josep Dalmau Carles quien, además de desarrollar labores docentes ${ }^{63}$ se convertirá en 1904 en editor, especializándose en producciones cartográficas y también en la elaboración de manuales escolares, muy difundidos en su momento en España y en Hispanoamérica. ${ }^{64}$

\section{Editoriales extranjeras}

Los mapas procedentes de casas editoriales extranjeras suman 46 cartas con un claro dominio de tres empresas: la milanesa Antonio Vallardi, la austríaca G. Freytag \& Berndt y la parisina Librairie Delagrave (figura 3) sumando entre ellas más del 65\% del total de producciones foráneas.

Figura 3. Reproducciones totales cartográficas por casas extranjeras

\begin{tabular}{|r|c|}
\hline Antonio Vallardi, Milán & 12 \\
\hline G. Freytag \& Berndt, Viena & 9 \\
\hline Librairie Delagrave, París & 9 \\
\hline Dietrich Reimer y Ernst Vohsen, Berlin & 4 \\
\hline Hilmar Klasing \& Co. Georg Lang,... & 3 \\
\hline Justus Perthes, Gotha & 2 \\
\hline Bundensandstalt für Bodenforschung,... & 2 \\
\hline Kunzli Hermanos, Zúrich & 1 \\
\hline Editorial Vallardi Americana, Buenos... & 1 \\
\hline Georg Westermann, Braunschweig & 1 \\
\hline G. B. Paravia e Comp., Turín & 1 \\
\hline Librairie Hatier, París & 1 \\
\hline
\end{tabular}

Fuente: elaboración propia.

\footnotetext{
${ }_{62}$ Para la datación de mismo se ha utilizado: http://iespadreisla.centros.educa.jcyl.es/sitio/index. cgi?wid_seccion=1\&wid_item=191 (consultado el 11/06/2020).

${ }^{63}$ Eduardo Connolly de Pernas, «Josep Dalmau Carles», Hibris: revista de bibliofilia, 34 (2006): 37-40.

${ }^{64}$ Emilio Castillejo Cambra, «Edición escolar en España, identidad, cultura política y contexto: la Enciclopedia Dalmau Carles-Pla», Historia y Memoria de la Educación, 6 (2017): 487-521. http://revistas.uned.es/index.php/HMe/article/view/17139 (consultado el 10-07-2020).
} 
En conjunto, las editoriales italianas aportan más de un $28 \%$ de los mapas extranjeros conservados (13 cartas en total). Antonio Vallardi Editore, sita en Milán, edita mapas en las décadas de los años cuarenta y cincuenta del siglo XX. La mayor parte de los que se conservan en el centro están confeccionados por Giulio Maranesi, algunos traducidos al castellano. Aunque sus raíces como productora de material didáctico y científico se sitúan a finales del siglo XVIII, la editorial en sí, bajo el nombre de Antonio Vallardi Editore, nace a mediados del siglo XIX, en 1843. Sus trabajos fueron prolijos, como constatan las producciones cartográficas en el instituto Ramón y Cajal de Huesca, los trabajos de ilustraciones ${ }^{65}$ para ciencias naturales ${ }^{66}$ y algunas láminas producidas a principios del siglo XX, conservadas en el Museo de Teruel. ${ }^{67}$

De procedencia germana, con 12 mapas, destaca la casa berlinesa Dietrich Reimer y Ernst Vohsen que publicará las cartas más antiguas que se conservan en el instituto conquense. Se trata de los "Kiepert», aún con una arcaizante y espectacular representación del relieve mediante normales. A este geógrafo (1818-1899) se le considera uno de los cartógrafos académicos más destacados de la segunda mitad del siglo XIX. Sus labores le llevaron a trabajar junto a Carl Ritter (1779-1859) con quien elaboró una prolífica colección de atlas de corte fundamentalmente histórico. ${ }^{68}$ Un buen ejemplo de sus mapas académicos (mapas murales para escuela, mapas de revistas académicas y atlas) detallados de Alemania y del Imperio Otomano se pueden visualizar en la Biblioteca de la Universidad de Chicago. ${ }^{69}$

En Leipzig radicaba la editorial de Georg Lang y Hilmar Klasing \& Co. que publicó numerosos materiales didácticos. En sus mapas se aunó la prestigiosa labor de cartógrafos y editores, como Georg Lang y el Instituto Geográfico y Litográfico de Eduard Gaebler. Los resultados

\footnotetext{
${ }^{65} \mathrm{http}: / /$ www.bpej.udg.mx/map_busc3?id=363 (consultado el 11-06-2020).

${ }^{66}$ Rosa María Castejón Arqued y Josep Pons Granja «Las placas de linterna del Departamento de Geografía de la Universidad de Barcelona»,Ar@cne, 178 (2013).http://www.ub.edu/geocrit/aracne/ aracne-178.htm (consultado el 10-07-2020).

67 https://www.dpteruel.es/DPTweb/la-exposicion-la-linterna-de-aristoteles-ies-vega-del-turia-170anos-de-ciencia-y-educacion-recibe-un-total-de-3-802-visitantes/ (consultado el 11-06-2020).

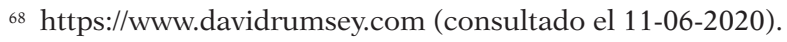

${ }^{69}$ https://www.lib.uchicago.edu/e/collections/maps/kiepert/ (consultado el 11-06-2020)
} 
obtenidos fueron de gran calidad, como atestiguan los tres mapas que conserva el instituto Alfonso VIII, todos fechados entre 1919 y 1935.

La casa editorial alemana de Justus Perthes aporta únicamente dos mapas de similares características a los del Taschen Atlas ${ }^{70}$ y a los recogidos en el Spezial-Kart von Afrika. Algunos centros educativos, como el instituto Ramón y Cajal de Huesca, también conservan ejemplares de esta editora. ${ }^{71}$ En conjunto, estas cartas se datan antes de 1935. Las publicaciones de George Westermann también están representadas en nuestro instituto.

Francia aporta, en conjunto, una decena de cartas murales. De ellas, nueve pertenecen a la serie Cartes Murales Historiques, publicadas por la prestigiosa casa Librairie Delagrave, y fechadas en las primeras décadas del siglo XX. Fueron impresas por el taller de Michard (París) y confeccionadas por el Dr. Louis Casimir André. ${ }^{72}$ Estilísticamente responden a materiales elaborados, muy didácticos, donde dominan las tintas claras y los topónimos nítidos, facilitando su lectura. Sus fechas oscilan entre 1911 y 1940, dilatado periodo que se explica por sus continuas reediciones.

Fueron muy conocidos en la mayoría de los centros educativos del momento y constituirían la antesala, desde el punto de vista cronológico, de las producciones de Vicens Vives.

De la Librairie Hatier se conserva un único ejemplar: un abigarrado mapa político de Francia, fechado entre 1932 y 1935.

De Austria proceden nueve cartas de la productora G. Freytag \& Berndt, afincada en la ciudad de Viena. Se trata de mapas temáticos y cartografías históricas variadas, situados cronológicamente en la primera mitad del siglo XX. Esta editorial se creó en 1885 y muy tempranamente dedicó una especial atención al mercado hispano traduciendo a nuestra lengua varias de sus cartas murales. De hecho, su mapa más antiguo conservado en el centro, un mapa escolar de África, datado entre 1899

\footnotetext{
70 http://bdh.bne.es (consultado el 11-06-2020).

71 Juan Mainer Baqué, «Panel 6. Métodos de enseñanza y dotación de material didáctico», (2015). http://iesramonycajalhuesca.catedu.es/wp-content/uploads/2015/10/Panel_6.pdf (consultado 10-072020)

72 AA. VV. Biographie et liste des travaux de M. Louis André Hommage de ses collègues et amis. 24 février 1937. (Lille: Emile Raoust, 1937), 15.
} 
y 1910, ya está traducido al castellano. Tras la segunda Guerra Mundial el Dr. Luis Doporto Marchori colaboró activamente con ella. Este profesor, docente de la escuela superior de Magisterio de Madrid, ${ }^{73}$ fue también alcalde de Teruel y, durante la Segunda República, gobernador civil de Ciudad Real y Valencia. En el terreno cartográfico, fue director del Instituto Geográfico, Catastral y de Estadística. Por sus actividades políticas fue represaliado por el nuevo régimen franquista, en 1939, y se exilió en México. Freytag \& Berndt aprovechó el prestigio internacional y la indudable formación de este geógrafo exiliado. El instituto conquense custodia cinco cartas de este periodo, fechadas entre 1945 y 1958. Las otras tres producciones de la editorial vienesa, dos mapas europeos y uno histórico, se editaron entre 1919 y 1933 y están en alemán.

De Suiza solo se cataloga un mapa realizado en los talleres de los hermanos Künzli y fechado entre 1919 y 1922. Finalmente, de Argentina se conserva otro único ejemplo, perteneciente a la editora Vallardi Americana, datado hacia 1950.

Muchos de estos materiales llegaron al centro por mediación de la casa distribuidora Cultura Eimler-Basante-Haase, con sede en Madrid y fundada a principios del siglo XX por Juan Eimler y a la que posteriormente se unieron Ramón Basanta y Pablo Haase. ${ }^{74}$ Se convirtió en una de las principales empresas distribuidoras de material científico y didáctico para las aulas. En el caso de la cartoteca del instituto Alfonso VIII suministró más del 12,5\% de todos los mapas.

\section{Producciones propias}

Parece lógico pensar que el primer mapa que debe manejar y ver todo niño debe ser aquel que él «mismo construya, porque es el único que le

\footnotetext{
${ }^{73}$ Rafael Sebastiá Alcaraz, «Competencias lingüísticas en la enseñanza de la geografía: de los manuales decimonónicos a Google Earth», en Geografía, educación y formación del profesorado (volumen II) María Jesús Marrón Gaite y María Luisa de Lázaro Torres (ed.) (Murcia: Asociación de Profesores de Didáctica de las Ciencias Sociales y Universidad Complutense de Madrid, 2010), 791804.

${ }^{74}$ Pedro Luis Moreno Martínez y José Pedro Marín Murcia «La casa comercial Cultura y la oferta de Material Pedagógico Moderno en España (1924-1934)», en Pedagogía museística: prácticas, usos didácticos e investigación del patrimonio educativo (Actas de las VI Jornadas Científicas de la Sociedad Española para el Estudio del Patrimonio Histórico-Educativo -SEPHE Ana María Badanelli Rubio y María Poveda Sanz (ed.) (Madrid: Universidad Complutense de Madrid, 2014), 523-532.
} 
pone en condiciones de entender los restantes». ${ }^{75}$ En esta línea, encontramos solamente dos ejemplares de producciones confeccionadas por los alumnos del instituto. No obstante, destaca la carta geográfica de la URSS, fechada aproximadamente hacia 1950, manuscrito y coloreado con exquisito cuidado (figura 4).

Figura 4. Carta manuscrita de la extinta URSS. Fecha: hacia 1950

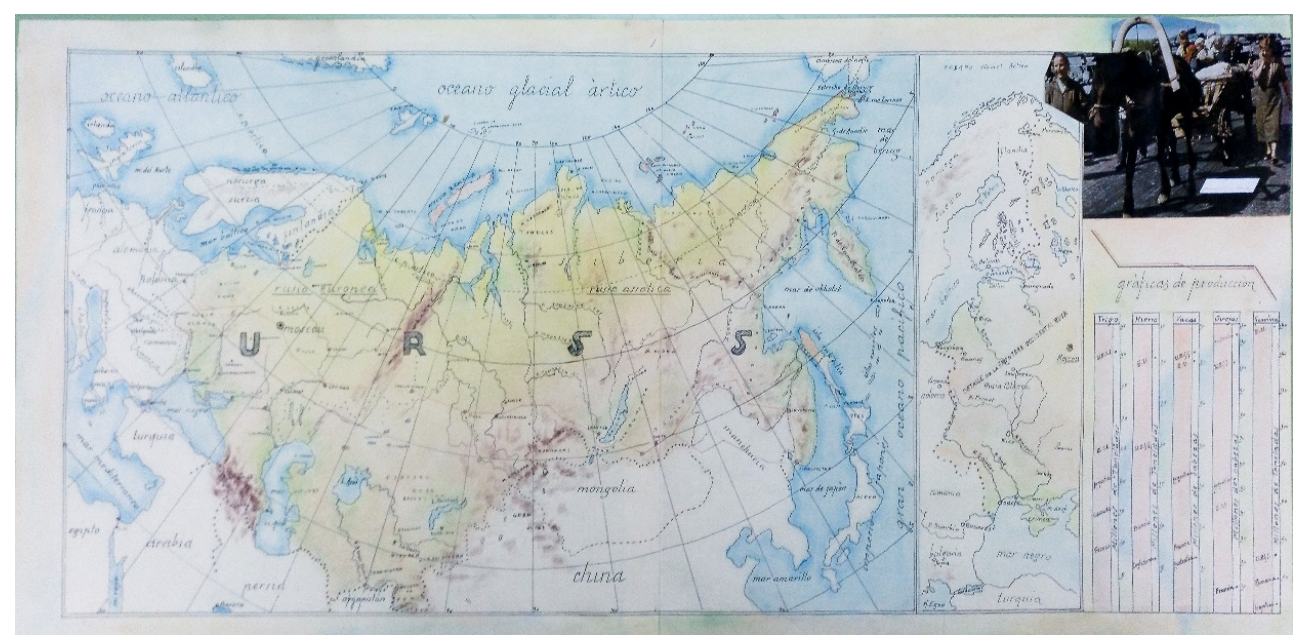

Fuente: Cartoteca Instituto Histórico Alfonso VIII.

Este alumno dibujó con brillantez un mapa de $28 \times 52 \mathrm{~cm}$ a escala 1:20.580.000, acompañándolo de los datos estadísticos del momento. Conectaba así la Geografía con la Estadística, recogiendo un aspecto muy usual en la elaboración de los atlas estadísticos de las primeras décadas del siglo XX. ${ }^{76}$ La composición resultante se articula en dos bloques. A la izquierda, dos mapas, uno de mayor tamaño, general y otro de detalle de las fronteras occidentales soviéticas. Ambos muestran la toponimia reconocible y el relieve representado por sombreado y tintas hipsométricas muy generales. Y a la derecha, en la parte inferior, los datos de producción soviética que han servido para la datación del mismo

\footnotetext{
75 Barnés, «El material de enseñanza», 202.

76 Leoncio López-Ocón, «La renovación de la enseñanza de la geografía en el instituto del Cardenal Cisneros de Madrid hacia 1912» en Biblio 3W. Revista bibliográfica de geografía y ciencias sociales, vol. XIX, n. ${ }^{\circ}$ 1071, (2014b). http://www.ub.edu/geocrit/b3w-1071.htm (consultado el 02-06-2020).
} 
entre 1946 y 1950, momento del cuarto Plan Quinquenal, y, en la parte superior, una imagen en color alusiva al campesinado ruso.

Además de esta producción, existe también un pequeño mapa en relieve de $28 \times 32 \times 4 \mathrm{~cm}$ de los alrededores de la ciudad de Cuenca, realizado en cartón coloreado, cuyo relieve se representa mediante curvas y capas hipsométricas. Se ignora la autoría del mismo y se fecha, con bastantes reservas, entre 1960 y 1980.

\section{La huella del alumnado en los mapas}

Parece admitido que las imágenes, en su conjunto, tienen un auténtico potencial educativo, como ya lo recogía Comenio en su libro Orbis Sensualium Pictus (El mundo sensible en imágenes) en el siglo XVII. Por ello, los mapas han sido profusamente utilizados en las aulas, y, sobre todo, los murales para llevar a cabo la labor de enseñanza de la Geografía, la Historia y otras materias. Muestra de ello son los cambios sufridos por los mapas con el paso del tiempo y de los alumnos.

Aparte del comprensible deterioro producido por el uso continuado a lo largo de muchos años y su inadecuada conservación, la impronta del alumnado se ha dejado notar mediante el subrayado y la escritura en las cartas geográficas, conformando así un auténtico anecdotario de curiosidades de la cartoteca. Algunos ejemplos notables corresponden con frases tales como «Arriba España Franco Franco Franco» escrito a lápiz sobre la mancha del mapa histórico del Imperio Romano de la editorial G. Freytag \& Berndt, que ya era antiguo por esas fechas, pues fue editado entre 1919 y 1923; el nombre y apellidos de otro alumno sobre el verso de la hoja de Huete del MTN, editada en 1942; o un breve «Feos 3. ${ }^{\circ} \mathrm{B}$ » en el verso del Mapa Físico de África que la casa austríaca citada más arriba publicó entre 1947 y 1956.

\section{CONCLUSIONES}

Los mapas de la cartoteca del IES Alfonso VIII son solo una parte de los recursos educativos con los que contaba la cátedra de Geografía e Historia. Se conservan otros, como una notable colección de placas epidoscópicas de vidrio de 10 x 8’5 cm sobre materias de Geografía, Ciencias Naturales e Historia del Arte, que asciende a cerca de 600 ejemplares. 
Está pendiente de catalogación y su análisis excedería la extensión de este artículo. Como también deben quedar fuera el resto de acciones desarrolladas en el centro en el campo patrimonial, que se enmarcan dentro de la labor llevada a cabo en el resto de institutos históricos de nuestro país. La mayoría de ellos pertenecen a la Asociación Nacional para la Defensa del Patrimonio de los Institutos Históricos (ANDPIH) ${ }^{77}$ que coordina y promueve la conservación, estudio y difusión del patrimonio educativo de estos centros. Esta asociación, por su incansable empeño en la recuperación del patrimonio educativo, fue distinguida en 2011 con la Corbata de la Orden de Alfonso X el Sabio y contribuye decididamente a «reconstruir y repensar el patrimonio de la educación como objeto histórico, el material y el inmaterial, al considerar que este acervo es un elemento cultural esencial» ${ }^{78}$ para toda la sociedad, como define bien Escolano.

La configuración de la cartoteca y su evolución es un fiel reflejo del resultado de su tiempo, pues ha estado sometida, en mayor o menor medida, a los diversos avatares y vicisitudes que han jalonado la historia de la ciudad de Cuenca y, en definitiva, del país. Se observa cómo las directrices oficiales, marcadas por las órdenes y normativas dictadas por el gobierno de turno para ser aplicadas en todos los centros de instrucción, chocaban continuamente con las limitaciones económicas de cada uno, que limitaron muchísimo la adquisición de materiales; en el caso que nos ocupa, una colección completa y actualizada de mapas. A pesar de ser unas herramientas fundamentales para el buen desarrollo de las clases de Geografía, las memorias de cada curso consultadas nos muestran esta dicotomía. No obstante, ello no fue óbice para que docentes comprometidos pusieran remedio a los mermados materiales de los gabinetes de Geografía, como hizo el profesor Pedreira apostando por recursos novedosos a la par que necesarios. El mapa de Oceanía de Kiepert, conservado desde su adquisición en los primeros años del siglo XX, es muestra viva de este empeño.

La consulta de esta documentación ha permitido, ante todo, constatar cómo ha sido el proceso de compra y acopio de instrumentos didácticos

\footnotetext{
77 https://www.asociacioninstitutoshistoricos.org/. (Consultado el 15-09-2021).

78 Agustín Escolano Benito «Cultura material de la escuela e historia intelectual», ETD: Educaçao Temática Digital, 22 (4), (2020), 795, consultado el 15-09-2021, doi: 10.20396/etd.v22i4.8660176.
} 
para la cátedra y el gabinete primero y el departamento de Geografía, después, del centro, intentando subsanar posibles carencias didácticas y materiales en el centro educativo. Igualmente, demuestra que la evolución del repertorio cartográfico, como el del resto de materiales didácticos, no ha sido lineal. Circunstancias externas, como la Carlistada de 1874, e internas, como el deterioro por el uso y la pérdida de materiales, han hecho variar este repertorio.

La colección actual de mapas que conforma la cartoteca del IES Alfonso VIII nos muestra dos características relevantes. Por un lado, el predominio de producciones extranjeras -europeas-, hasta los años cuarenta y cincuenta del siglo pasado: la mayor parte de esos mapas procede de Italia, Alemania, Francia y Austria principalmente. Por otro, después de la década de los cincuenta, el protagonismo en el suministro será para las casas editoras peninsulares (Vicens Vives, Aguilar, Teide, IGC). Se demuestra también que, a partir de la posguerra española, se abandonan las producciones en su lengua vernácula para pasar a elegir cartografías que, aunque producidas fuera de España, estén editadas en castellano.

La catalogación de los mapas ha permitido sacar a la luz un auténtico ejemplo de patrimonio histórico y cartográfico para el centro conquense, especialmente en sus ejemplares anteriores a la Guerra Civil, y verdaderamente destacable entre los institutos históricos españoles. De ahí la importancia cultural que esta colección encierra en sí misma, por haber sido testigo evidente del paso del tiempo y de las diversas técnicas y recursos didácticos utilizados en los procesos de enseñanza en el aula. Se convierte así en un espacio de patrimonio, a modo de museo, a la par que en un potente recurso didáctico en donde se aprende mediante la observación y el disfrute de las piezas expuestas, entendiéndolas dentro de un proceso histórico global, de una praxis docente en la que la cartografía ha formado parte esencial.

La apuesta por la inclusión de una educación patrimonial, volviendo la mirada hacia los institutos históricos y su legado tangible e intangible, ayudaría a consolidar un concepto escasamente presente en la mayoría de los currículos vigentes de educación secundaria: el patrimonio cultural. Hoy en día, el mapa mural, entendido como esa cartografía «frontal» situada delante de los alumnos, prácticamente ha desaparecido de 
las aulas. En su lugar, los recursos actuales usan las nuevas tecnologías en la red, el GPS y los SIG, todo a través de la pantalla digital. Esto justifica aún más, si cabe y a nuestro modo de ver, el peso cultural y patrimonial de las producciones cartográficas históricas, presentes en estos lugares de memoria.

\section{Nota sobre los autores}

Óscar Serrano Gil es licenciado en Humanidades y doctor en Geografía por la Universidad de Castilla-La Mancha. Ha desarrollado principalmente sus tareas docentes en la Universidad de Castilla-La Mancha en las Facultades de Educación de los campus de Toledo y Cuenca donde, además de impartir docencia en asignaturas vinculadas a la Didáctica de las Ciencias Sociales en los grados de Educación Infantil y Primaria, ha desempeñado funciones de tutor para los prácticums y los Trabajos Fin de Grado. Ha actuado como moderador, ponente y secretario de algunos cursos de verano y ha colaborado también en el programa universitario para mayores «José Saramago». Actualmente es profesor en la Facultad de Formación del Profesorado y Educación de la Universidad Autónoma de Madrid.

La versatilidad de los estudios en Humanidades justifica que los campos y las líneas de investigación más destacadas de sus publicaciones científicas y contribuciones a diversos congresos sean: el estudio del paisaje y el patrimonio, los espacios naturales protegidos, el desarrollo rural y socioeconómico del territorio, y la didáctica de la Geografía. Ha participado como miembro de equipos de investigación de varios proyectos, algunos de ellos, estrechamente relacionados con la temática central de su tesis doctoral.

Jesús López Requena es licenciado en Prehistoria y Arqueología por la Universidad Autónoma de Madrid y, actualmente, profesor en el IES Alfonso VIII de Cuenca, donde es uno de los responsables del proyecto «IES Alfonso VIII, instituto histórico», que gestiona el patrimonio educativo del centro. Fue director de las excavaciones del Cerro del Castillo (Reíllo) y la villa medieval de Moya. Ha realizado la Catalogación del Patrimonio Arquitectónico y Urbanístico del Conjunto Histórico-Artístico de la Villa de Moya (Cuenca) y es coautor de la «Guía del patrimonio 
Cultural de Castilla-La Mancha» (2011, Junta de Comunidades de Castilla-La Mancha) además de algunos artículos sobre Arqueología y Patrimonio. En la actualidad sus líneas de investigación se centran en la Telegrafía Óptica y en la Cartografía Histórica, temas sobre los que ha publicado tanto libros como artículos, participado en congresos y disertado en conferencias. Comisarió la exposición «Cartografía Histórica de la provincia de Cuenca», realizada por la Diputación Provincial conquense. Desde 2020 es académico de número de la Real Academia Conquense de Artes y Letras. Muy recientemente se ha incorporado, como investigador externo, al Proyecto de Investigación «Sistemas Complejos en Ciencias Sociales» de la Universidad de Alcalá de Henares.

\section{REFERENCIAS}

Aranaz del Río, Fernando. Tu amigo el mapa. Madrid: Instituto Geográfico Nacional, 2010.

Barnés, Domingo. «El material de enseñanza». Boletín de la Institución Libre de Enseñanza, XLI, 688 (1917):199-203.

Boletín Oficial de Instrucción Pública serie 2. ${ }^{a}$ tomo VII, n. ${ }^{\circ} 13$, (15 de octubre de 1844): 636-637.

Bosque Maurel, Joaquín. "Odón de Buen (1863-1945)». Boletín de la Real Sociedad Geográfica, CXXXIX-CXL (2003): 267-292.

Castejón Arqued, Rosa y Josep Pons Granja. «Las placas de linterna del Departamento de Geografía de la Universidad de Barcelona».Ar@cne. Revista electrónica de recursos en Internet sobre Geografía y Ciencias Sociales, 178 (2013), http://http://www.ub.edu/geocrit/aracne/aracne-178.htm.

Castillejo Cambra, Emilio. «Edición escolar en España, identidad, cultura política y contexto: la Enciclopedia Dalmau Carles-Pla». Historia y Memoria de La Educación, 6 (2017): 487-521.

Comenio, Juan Amós. Didáctica Magna. México: Porrúa, 1998.

Connolly de Pernas, Eduardo. «Josep Dalmau Carles». Hibris: Revista de Bibliofilia, 34 (2006): 37-40.

Domínguez Mallo, Lorena. «Leopoldo Pedreira Taibo, intuición historiográfica e virulencia crítica». Galicia21 Journal of Contemporary Galician Studies, D (2012): 27-43.

Escolano Benito, Agustín. «Cultura material de la escuela e historia intelectual», ETD: Educaçao Temática Digital, 22 (4), (2020): 793-811, doi: 10.20396/ etd.v22i4.8660176. 
Fabre, Anna y José Luis Villanova. «Jaume Vicens Vives. 1910-1960». Geographers. Biobibliographical Studies, 17 (1997): 62-105.

Fernández Cursach, Jaime. «Apuntes para una historia del Alfonso VIII. Los orígenes del instituto». Olcades. Temas de Cuenca vol. I, 5 (1981): 235-248.

Fernández Cursach, Jaime. «Apuntes para una historia del Alfonso VIII. La cuestión del local». Olcades. Temas de Cuenca vol. II, 9 (1982):123-134.

González Izquierdo, María Jesús. «El instituto histórico de Cuenca. Aproximación histórica». En Actas de las V Jornadas de Institutos Históricos Españoles, celebradas en Cabra (Córdoba) del 6 al 8 de julio de 2011. 103-114. Cabra: Fundación Aguilar y Eslava, 2012.

Guijarro Mora, Víctor. Artefactos y acción educativa. La cultura del objeto científico en la enseñanza secundaria en España (1845-1930). Madrid: Dykinson, 2018.

Hernando Rica, Agustín. «La educación de un geógrafo. Propuestas históricas de planes de estudio de Geografía en España». Revista de Geografía XXIX, (1995): 37-67.

Líter Mayayo, Carmen y Carmen García Calatayud. Materiales cartográficos: manual de catalogación. Madrid: Arco Libros, 1999.

López-Ocón, Leoncio. «La renovación de la enseñanza de la geografía en las aulas de bachillerato en los primeros años del siglo XX» en Aulas modernas Nuevas perspectivas sobre las reformas de la enseñanza secundaria en la época de la JAE (1907-1939), editado por Leoncio López-Ocón, 77-118. Madrid: Universidad Carlos III, 2014.

López-Ocón, Leoncio. «La renovación de la enseñanza de la Geografía en el instituto del cardenal Cisneros de Madrid hacia 1912». Biblio 3W. Revista Bibliográfica de Geografía y Ciencias Sociales XIX, 1071 (2014). http://www. ub.edu/geocrit/b3w-1071.htm.

Mainer Baqué, Juan. Panel 6. Métodos de enseñanza y dotación de material didáctico. Actualizado 2015. http://iesramonycajalhuesca.catedu.es/wp-content/uploads/2015/10/Panel_6.pdf

Martín López, José. Cartógrafos españoles. Madrid: Centro Nacional de Información Geográfica. Instituto Geográfico Nacional, 2017.

Merchán Iglesias, Francisco Javier, Olga Duarte Piña y Nicolás de Alba Fernández. «La enseñanza de la historia como formación para la participación ciudadana», en Educar para la participación ciudadana en la enseñanza de las Ciencias Sociales, coordinado por Nicolás de Alba Fernández, et. al., 193202. Sevilla: Asociación de Profesores de Didáctica de las Ciencias Sociales: Diada, 2012.

Moreno Martínez, Pedro Luis y José Pedro Marín Murcia «La casa comercial Cultura y la oferta de Material Pedagógico Moderno en España (19241934)», en Pedagogía museística: prácticas, usos didácticos e investigación 
del patrimonio educativo (Actas de las VI Jornadas Científicas de la Sociedad Española para el Estudio del Patrimonio Histórico-Educativo) coordinado por Ana María Badanelli Rubio et al., 523-532. Madrid: Universidad Complutense de Madrid, 2014.

Orellana Álvarez, María Francisca. «El mapa y la formación del profesorado. Aportaciones sobre la cartografía en revistas y sugerencias bibliográficas». Didáctica Geográfica, 5 (2002): 11-41.

Puyol, R. y José Estébanez. Análisis e interpretación del mapa topográfico. Madrid: Tebar Flores, 1976.

Santirso Rodríguez, Manuel. «Los atlas históricos en la España contemporánea: una exploración». Scripta Nova. Revista Electrónica de Geografía y Ciencias Sociales XV, 365 (2010). http://www.ub.edu/geocrit/sn/sn-365.htm.

Sebastiá Alcaraz, Rafael. «Competencias lingüísticas en la enseñanza de la geografía: de los manuales decimonónicos a Google Earth». En Geografía, educación y formación del profesorado, volumen II, editado por M. ${ }^{a}$ J. Marrón y M. ${ }^{a}$ L. de Lázaro, 791-804. Madrid: Grupo de Didáctica de la Geografía (Asociación Española de Geografía), 2010.

Valls Montés, Rafael. «La institución libre de enseñanza y la educación histórica: Rafael Ballester y la renovación historiográfica y didáctica españolas de inicios del siglo XX». Historia de La Educación, 31 (2012): 231-256.

Velasco Tirado, Ana. «Recursos educativos de cartografía, geografía y ciencias de la tierra del Instituto Geografía Nacional». En La reconfiguración del medio rural en la sociedad de la información, editado por X. C. Maciá Arce et al., 467-480. Madrid: Grupo de Didáctica de la Geografía (Asociación Española de Geografía), 2019.

Villanova, José Luis. «La cartografía en la obra de Jame Vicens Vives». Estudios Geográficos, 59 (1988): 711-737.

Zamoro Madera, Ángel. D. Tomás Escriche y Mieg, 1844-1935: profesor de segunda enseñanza (1869-1918). Badajoz: Diputación de Badajoz, 2015. 